
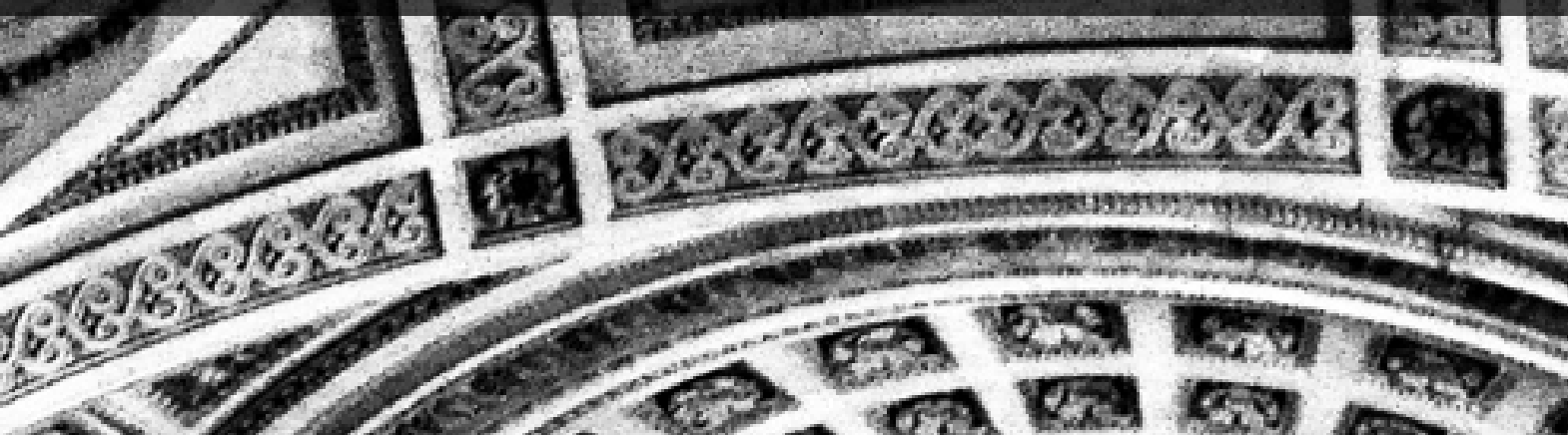

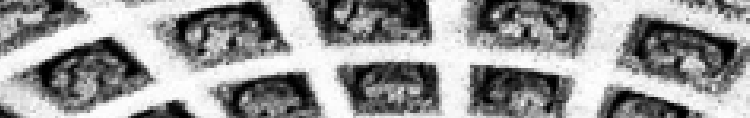
$20 \cos 16$

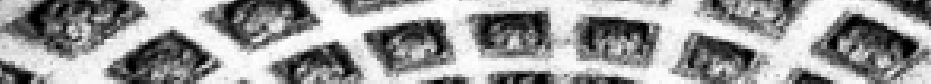

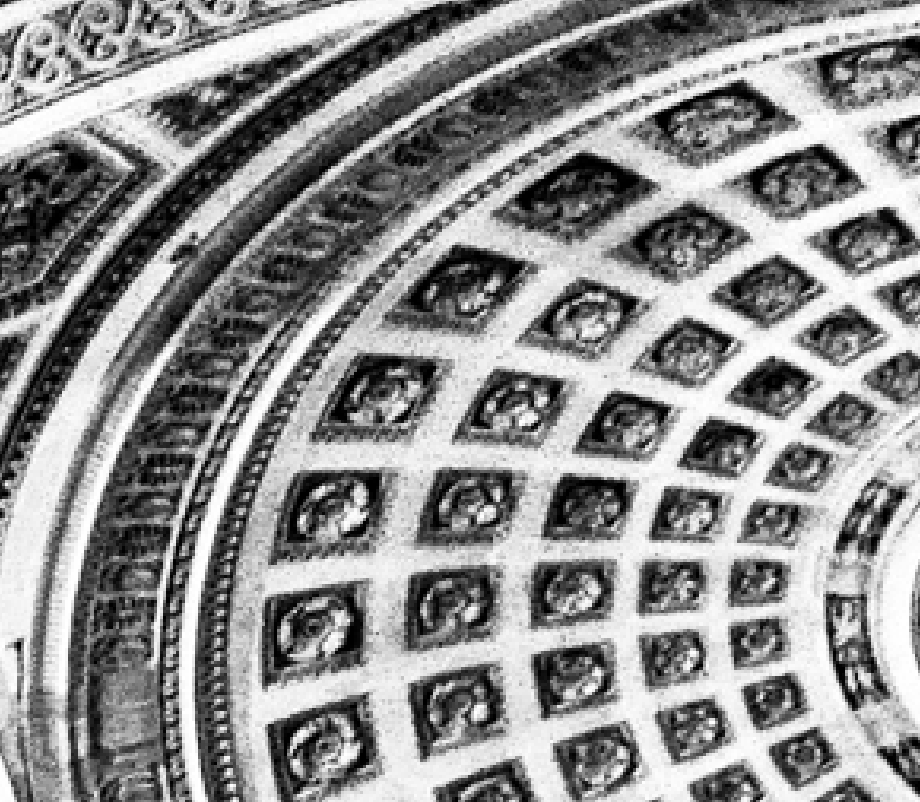

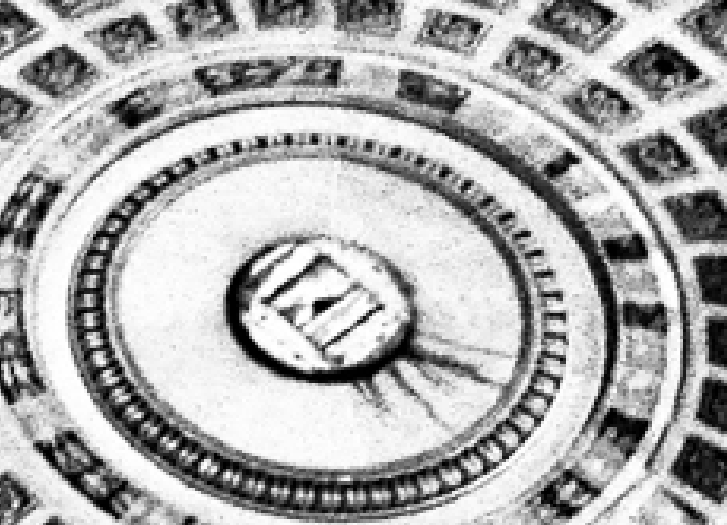

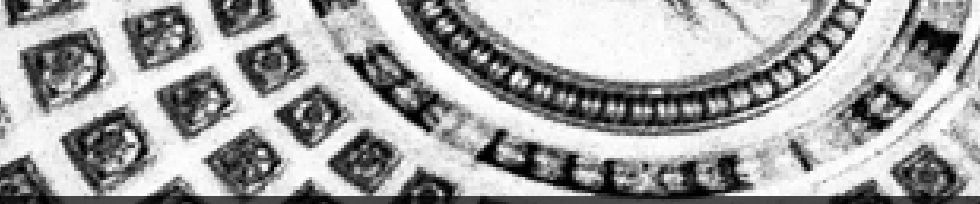

\title{
Corpos ábjetos: put a ring on it
}

Abject bodies: put a ring on it

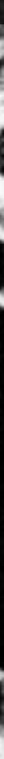




\section{[ANA C. B. M. PASSOS]}

Joalheira e doutoranda no programa de pós-graduação em Educação, Arte e História da Cultura da Universidade Presbiteriana Mackenzie (SP).

\section{E-mail: anacristina@anapassos.art.br}

[resumo] 0 anel de noivado pode ser compreendido como um marcador de gênero ao deixarmos de lado quaisquer aspectos românticos de sua dádiva e de sua posse. Este artigo pretende refazer o percurso histórico da construção de seu significado e tecer algumas considerações sobre sua exibição nas redes sociais por celebridades e anônimas para demonstrar que o corpo feminino desprovido de um anel de diamante ou de uma aliança pode ser considerado um corpo abjeto na sociedade contemporânea.

[abstract] The engagement ring can be understood as a gender marker by leaving aside any romantic aspects of its gift and possession. This article intends to retrace the historical construction of its meaning and to make a few considerations about its exhibition in the social networks by celebrities or anonymous, in order to demonstrate that the feminine body devoid of a diamond ring or simply a wedding band can be considered an abject body in the contemporary society.

[keywords] gjewelry; body; gender; history; material culture. 


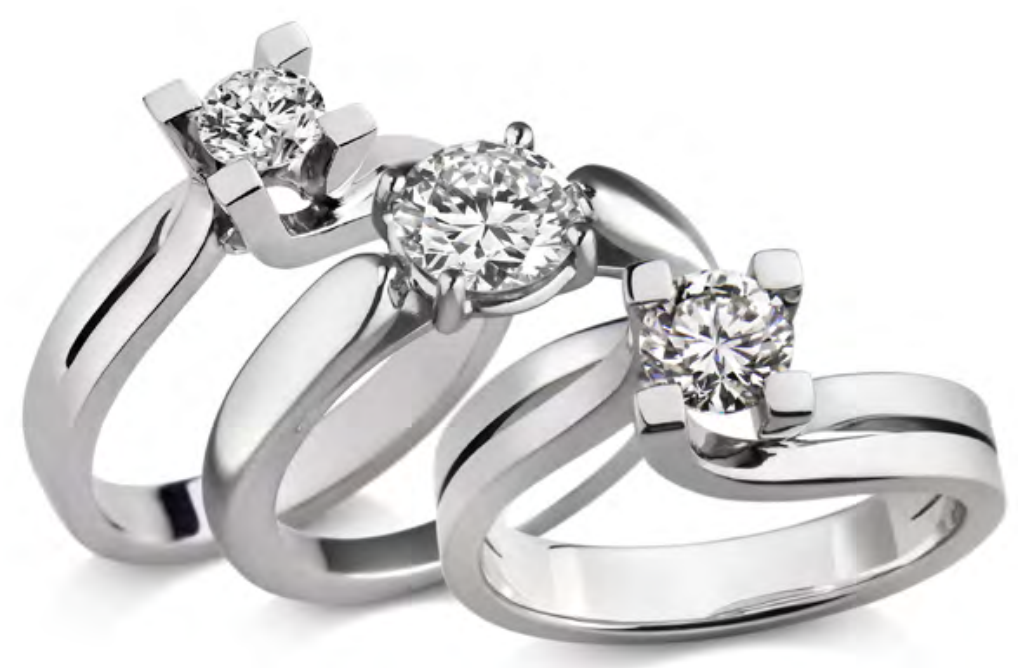

Figura 1 - Anéis de noivado de ouro branco com diamantes. Foto: José Terra.

Fonte: Arquivo pessoal.

Um novo marcador de gênero globalizado

Em um mundo espetacular, fetichizado, plastificado (TIBURI, 2015), não é de estranhar que mulheres façam intervenções cirúrgicas para exibir seus anéis de diamante. Se já tivemos o surgimento da cirurgia estética intima, por que não outra específica para a selfie com o anel de noivado dos sonhos? Há que se plastificar a mão para fazer a foto perfeita ou para apresentar aos outros o troféu de vencedora (ELLIN, 2014). Em seguida, basta ler um dos guias de como mostrar discretamente o seu anel. Os truques são simples: ajeitar uma teimosa mecha de cabelo, verificar se colocou os brincos, fazer uma cara pensativa levando a mão ao rosto, proteger os olhos do sol, segurar alguma coisa com as duas mãos, tocar no rosto do felizardo, gesticular bastante e, se nada der certo, esfregar o desejado anel na cara dos outros sem pudor. Feito isso, a fotografia perfeita estará garantida (BRIDES, 2015).

No Brasil, até muito pouco tempo atrás, 0 anel de noivado era a aliança de casamento usada na mão direita. Mais tarde, no casamento, ela passava para a mão esquerda com uma discreta inscrição interna com o nome do cônjuge e a data da cerimônia. Entretanto, de alguns anos para cá, muitas mulheres têm sido vistas com enormes, ou não tão enormes, diamantes no dedo anular da mão esquerda.

A empresa de consultoria estratégica Bain \& Co. realizou uma pesquisa global sobre o crescimento da indústria joalheira e constatou que a aquisição de um anel de diamante como anel de noivado, um fenômeno inicialmente norte-americano, vem rapidamente tornando-se global, alterando hábitos de consumo e até mesmo a percepção sobre o pedido de casamento (BAIN, 2012). De onde vem essa tradição inventada (GIDDENS, 2011) e agora multiplicada?

Anel de diamante: uma tradição inventada

0 primeiro anel de noivado com diamante de que se tem notícia foi dado por Maximiliano I da Áustria para Maria de Borgonha, em 1477, entregue por 
um emissário como símbolo de compromisso. Aparentemente, o que estava em jogo nessa ocasião era o acordo entre os nobres e um presente à altura de duas importantes casas reais. Passaram-se séculos até que 0 anel de diamante viesse a significar o desejo de uma união duradoura. Muito antes disso, os egípcios usavam plantas das margens do rio Nilo com as quais davam um nó no dedo, representando união e prosperidade. Romanos usavam um simples aro de ferro que simbolizava a força da união. Em ouro, era feito $o$ anel Fede, que apresentava um aperto de mão (dextrarum iunctio), selava um compromisso e significava lealdade. Inicialmente um símbolo de amizade, entre os séculos XII e XVIII, ele foi usado na união entre um homem e uma mulher. Já o anel Gimmel era composto de dois aros que se combinavam, formando um só desenho. 0 anel irlandês Claddagh trazia entre duas mãos um coração sobre o qual repousava uma coroa, significando amizade, amor e lealdade, respectivamente. Na Turquia, surgiu o anel Puzzle (quebra-cabeça) formado por três ou mais aros de combinação tão intrincada que, caso fosse tirado do dedo, dificilmente uma mulher conseguiria colocá-lo novamente sozinha, em uma demonstração de propriedade do homem sobre o corpo da mulher. Havia anéis de noivado (anulus pronubus) entre os primeiros cristãos no periodo bizantino e por toda a Europa durante a Idade Média, mas somente com o Concilio de Latrão, em 1179, o casamento cristão ganhou dimensão religiosa assim como 0 anel de noivado no dedo anular esquerdo (PERRET, 2012).
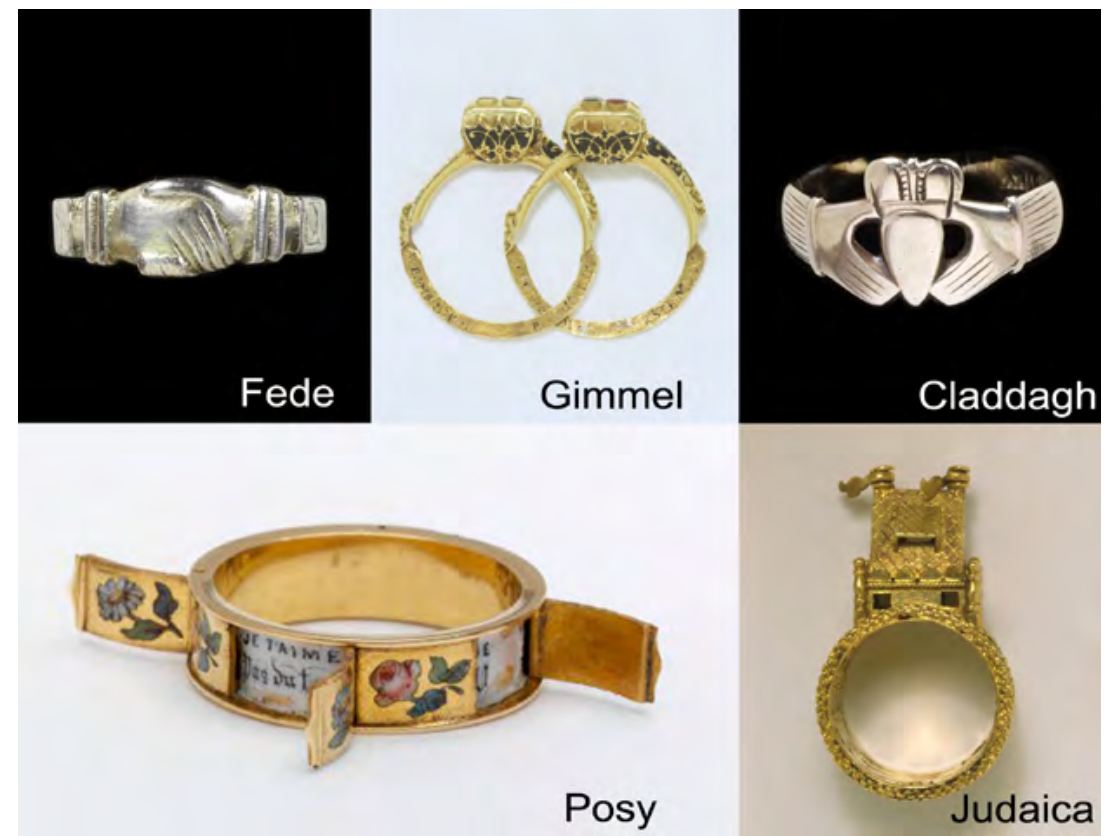

Figura 2 - Anéis Fede, Gimmel, Claddagh, Posy e de congregação judaica. Foto: ๑ Victoria and Albert Museum, Londres. Fonte: V\&A Museum Jewellery Collection Online'.

Alguns anéis eram meramente simbólicos e sequer pertenciam aos noivos ou suas famílias. É o caso do anel pertencente às congregações judaicas de Veneza e da Alemanha do século XVI, usado apenas durante as cerimônias de casamento. Ele representava um templo, um castelo ou uma casa e, por derivação, o novo lar que se formava. Em alguns momentos da história, os anéis de noivado eram ricos e extravagantes; em outros, muito singelos, quase poé- 
ticos. Este era o caso dos anéis ingleses Posy (posie ou poesy) dos séculos XV e $\mathrm{XVI}$, que tinham aros simples nos quais frases de amor eram gravadas interna ou externamente. 0 amor romântico fez com que algumas raras mulheres de posses também dessem anéis a seus amantes. Este foi o caso de Maria Antonieta que deu um anel com uma flor-de-lis para seu amante, o conde Axel Fersen, e mandou fazer para si mesma um anel com o brasão da família dele e a inscrição Tutto a te me guida. Elizabeth I, muito antes, já havia presenteado Robert Devereux com um anel de ouro. No período elisabetano, surgiu a distinção entre os anéis decorativos e os de compromisso. Um pouco depois, no século XVII, os puritanos ingleses e americanos, contrários às frivolidades, substituiram os anéis de noivado por dedais que representavam os afazeres domésticos das mulheres que se casavam (SCARISBRICK, 2013).

Nos últimos dois séculos, os anéis de noivado tornaram-se algo comum e foram realizados nos mais diversos materiais: rubis, safiras, esmeraldas e todas as demais gemas coloridas, sempre conforme o gosto e as posses dos noivos. Entre a nobreza europeia é costume dar anéis com safira, que representa o desejo de um filho primogênito. Provavelmente, o mais famoso deles é 0 anel de Lady Diana Spencer, que atualmente pertence à sua nora Catherine, duquesa de Cambridge ${ }^{2}$. Outras gemas podem simbolizar a família dos noivos ou o seu país, como o caso do príncipe herdeiro da Casa de Orange que, em 2001, deu à sua noiva um anel com um diamante de cor laranja ${ }^{3}$. Entretanto, em algum momento, os diamantes passaram a ser concebidos como o verdadeiro símbolo do amor eterno. Como isso aconteceu?

A palavra diamante vem do grego ả $\delta \breve{\mu} \mu \bar{\alpha} \varsigma$ (adámas), que significa inconquistável, inquebrável, e, de fato, essa é a gema existente de maior dureza. Utilizada também na indústria como matéria-prima abrasiva ou em peças que devem suportar grandes desgastes, seu uso mais conhecido é na joalheria. Não há nada mais fascinante do que um diamante bem lapidado sob a luz do sol, ou mesmo sob a luz artificial. A lapidação brilhante redonda, com 58 facetas e que permite a máxima refração da luz por todo o diamante, surgiu apenas em 1750 pelas mãos de Vicenzio Peruzzi e ganhou sua forma atual em 1919, com o trabalho de Marcel Tolkowsky (POST, 1997). Foi em 1886 que a joalheria norte-americana Tiffany \& Co. apresentou a estrutura com seis garras em platina ${ }^{4}$ e o solitário ganhou os contornos que conhecemos hoje, montado de forma que a luz atravesse a gema e mostre seu fogo interno, como é chamado esse brilho indescritivel (TIFFANY \& CO, 2015). 0 anel de noivado, no século XX, foi um objeto de fascínio por sua beleza, mas também um símbolo de status, uma prova de amor, funcionando como promessa de casamento que tem valor de contrato perante a sociedade, hoje alcançada pelas redes sociais.

0 diamante é muito bonito e duradouro. Ele é a gema mais rara e cara de todas também, mas isso tem um motivo que, novamente, é uma razão inventada. A raridade dos diamantes se constitui a partir da formação de um poderoso cartel que controla toda a produção de diamantes brutos do mundo, com exceção de parte das produções australiana e canadense e dos chamados diamantes de sangue oriundos de mineração e comercialização irregular em paises africanos em guerra. 
Por conta da Grande Depressão, em 1929, Ernest Oppenheimer, presidente da mineradora De Beers, decidiu, seguindo os passos de seu predecessor - que já havia criado mecanismos de controle de oferta de diamantes brutos para manter os valores de mercado estáveis -, manipular também a demanda de consumo, particularmente nos Estados Unidos, que não haviam sido tão duramente afetados pela Primeira Grande Guerra. Para isso, em 1938, ele contratou a agência de publicidade N. W. Ayer. Seu objetivo era simples: relacionar os diamantes com o amor e a eternidade. Até esse momento, os anéis de noivado utilizavam gemas muito pequenas e baratas. Hollywood ficou incumbida de relacionar romance e glamour com diamantes. Campanhas na imprensa e nas rádios promoviam a ideia de que os momentos iniciais de romance são breves, mas os diamantes duram uma eternidade (SULLIVAN, 2013). Aproveitando a Segunda Grande Guerra, campanhas pediam apoio aos esforços de guerra por meio da compra de anéis de noivado, que ajudariam a financiar os diamantes que iriam para a indústria. Soldados compravam anéis de diamantes para suas amadas a fim de que eles tivessem para quem retornar e, caso isso não acontecesse, elas teriam algum recurso para recomeçar suas vidas (OLTUSKI, 2011). A joia não é um investimento seguro, mas sempre foi uma reserva de valor em tempos dificeis.

A De Beers não tinha concorrência e era a maior fornecedora mundial de diamantes brutos. Sua campanha era de ideias e, entre 1938 e 1941, as vendas subiram 55\%. Não satisfeitos, eles organizaram tours pelas escolas a fim de formar uma nova geração de consumidores. A formação dos diamantes no interior da terra e os motivos de sua suposta raridade eram detalhadamente explicados. Foi criado o critério dos 4Cs para auxiliar na escolha da gema ideal e justificar seu valor exorbitante: cor, claridade, corte e peso (carat). Em 1947, em pleno pós-guerra, Frances Gerety, redatora da agência de publicidade, criou a campanha $A$ diamond is forever (Um diamante é para sempre), considerada o slogan do século XX. Em uma coincidência mais do que oportuna, houve uma mudança na legislação norte-americana que estabeleceu os bens pertencentes a uma mulher em caso de separação (OLTUSKI, 2011). A letra da música Diamonds are a girl's best friend, que ficou famosa na voz de Marilyn Monroe no filme de Howard Hawks, Os homens preferem as loiras, de 1953, foi composta por Jule Styne e Leo Robin para um musical homônimo em 1949 e é explícita ao revelar o verdadeiro papel dos diamantes na vida de uma mulher:

Eu prefiro um homem que vive e dá joias caras. Um beijo na mão pode ser bastante europeu, mas os diamantes são o melhor amigo de uma menina. Um beijo pode ser nobre, mas não vai pagar o aluguel de seu humilde apartamento ou ajudá-la na máquina de vendas. (HABERMAS, 2011, p. 96 - tradução nossa) ${ }^{5}$

Nessa mesma época, a empresa criou subsidiárias no mundo todo para fugir do embargo à África do Sul e sua política de apartheid. A Diamond Trading Company segue até hoje como uma das maiores empresas de diamante do mundo, tendo criado, em 2005, uma marca varejista chamada Forevermark, que promete as mais bem lapidadas gemas e certificação de origem, o que 
descarta serem diamantes de sangue. A De Beers continua acreditando no poder do marketing na criação de novos desejos de consumo e hoje aposta no anel para a mão direita, o power ring, que seria comprado pela mulher em uma demonstração de poder sobre si mesma e sobre seu corpo, e até no anel comemorativo de um divórcio (MICHAULT, 2005).

Assim foi inventada uma tradição que faz com que $85 \%$ das mulheres norte-americanas casadas tenham pelo menos um anel de diamante, normalmente o seu anel de noivado, e que os homens gastem em média o equivalente a dois salários, podendo chegar a três, em sua compra (BAIN, 2012).

A sociedade do espetáculo transformou essa invenção em uma meta de vida e o culto às celebridades, junto com a penetração das redes sociais, tornaram-na uma febre mundial. Esses números fazem de toda norte-americana adulta sem um anel de noivado no dedo uma espécie de monstruosidade. 0 que há de errado com ela para que não tenha um diamante no dedo? É preciso corrigir essa anormalidade, sempre muito rapidamente, para não vermos a norma ser questionada. Não pode haver espaço para a instalação da dúvida.

\section{0 que significa o anel de diamante?}

Observemos um caso exemplar, mesmo que lendário. Em 1956, Grace Kelly, estrela de cinema, ficou noiva do príncipe Rainier Grimaldi de Mônaco, que havia conhecido durante as filmagens de Ladrão de casaca, de Alfred Hitchcock. Ele a pediu em casamento com uma aliança do modelo eternity, que tradicionalmente representa amor eterno. Ela era inteiramente rodeada de diamantes e rubis e foi comprada na joalheria Cartier. 0 pedido foi vastamente documentado e fotos foram publicadas em jornais e revistas do mundo inteiro. Ao visitá-la em Hollywood, nos Estados Unidos, Grimaldi se deu conta de que seu anel de noivado europeu não se encaixava nas exigências locais. Ele foi a uma loja da mesma joalheria e solicitou o maior diamante disponivel em seus cofres, tratando imediatamente de colocá-lo no dedo de sua noiva. Mais adequado aos padrões hollywoodianos, esse anel tinha um diamante central em lapidação esmeralda, pesando 10,5 quilates e ladeado por outros dois diamantes menores ${ }^{6}$. Ele é mostrado orgulhosamente no dedo da atriz em seu último filme, Alta sociedade, de Charles Walters, de 1956, antes de deixar o cinema para sempre. Tamanho, desde então, é uma questão relevante na aquisição de um anel de noivado. 0 diamante, que é avaliado em seus atributos físicos, torna-se predicado essencial na definição do tamanho dos sentimentos envolvidos e do poder econômico do casal.

Nicholas Frank Oppenheimer, neto de Ernest Oppenheimer, no fim do século passado, afirmou que os diamantes são intrinsecamente sem valor, exceto pela profunda necessidade psicológica que eles são capazes de preencher (MCNEIL, 1999). Mais do que a discussão sobre o valor intrínseco ou percebido da joia, verdade ou não, ele nos dá uma pista sobre a importância dessa prótese que as mulheres, agora mais do que nunca, tratam de colocar em seus dedos o mais rapidamente possivel. 
Ignorando por completo a origem dessa tradição, mulheres do mundo inteiro creem, de acordo com o que é apresentado nas campanhas internacionais de publicidade das grandes joalherias, que o amor verdadeiro pode ser contabilizado em quilates. Ambos, homens e mulheres, ficam absolutamente fascinados pelo brilho da gema e pelo seu status de pessoas bem sucedidas dentro da mais completa e perfeita heteronormatividade. Homens são provedores potentes e mulheres são troféus férteis. Essencialmente, estamos tratando da performatividade de gênero (BUTLER, 2007) em uma de suas formas mais exteriorizáveis e caras. Com sua aura vibrante - proveniente de seu tempo geológico, de sua história e da dificuldade de sua obtenção -, essa joia pode ser um grilhão que aprisiona quem a dá e quem a recebe.

Esse símbolo da identidade de gênero e do estado civil é colocado sobre o corpo como uma marcação da mulher que usa o anel para se tornar a mulher que pertence a alguém e a que existe para alguém (SLEDZIEWSKI, 2011). Ser, aparentar, transcender. Em que 0 anel de diamante pode ajudar essa mulher? Ele é uma forma de capital, de moeda de troca: recebido em troca de pertencimento marital e exclusividade sexual, com seu brilho também enfatiza a atratividade física, aumentando ainda mais o poder de sedução das mulheres sobre os homens.

Uma joia pode ser um capital simbólico, um meio de comunicação ao facilitar relações intersubjetivas. Pode significar uma reminiscência, uma distinção social, um talismã ou o pertencimento a um grupo. Liesbeth den Besten (2011), ao tratar de sua importância, explica que:

A joia é muitas vezes compreendida como um sinal, como um objeto que dá sentido. As pessoas estão acostumadas a ler joias (sic). Dito isto, devo acrescentar que é também o portador que cria o significado de uma peça, atribuindo-Ihe histórias, memórias e sua personalidade a ela, carregando uma peça de joalharia com significado. (sic) 0 significado das joias, mesmo de trabalhos autorais, é - mais do que normalmente pensamos ou queremos admitir - dependente de tradições subjacentes, atribuições e sistemas de valor que têm uma longa história; isto forma a própria linguagem da joia. (BESTEN, 2011, pp. 24-31- tradução nossa) ${ }^{7}$

\section{Uma imagem adequada para as redes sociais}

Seja uma tradição inventada ou não, as mulheres postam suas imagens em júbilo nas redes sociais. Elas constroem uma cena a partir de gestos e atitudes que falam diretamente desse papel social conquistado: o de mulher noiva e, mais tarde, casada. 0 convencionalismo desses gestos e atitudes explicita a construção social desses significados. Os anéis de diamantes as qualificam como mulheres e ajudam a identificá-las, embora as fotos não revelem quem são de fato, mas quem elas deveriam ser. Vilém Flusser define fotógrafo como aquela "pessoa que procura inserir na imagem informações não previstas pelo aparelho fotográfico" (FLUSSER, 2002, p. 77), mas será que ainda resta por onde vaguear nas selfies postadas no Instagram? Os atributos recebidos dessa 
prótese plástica - o diamante não deixa de ser mineral e tem um caráter estético também - são signos de nossa época aplicados sobre seus corpos, como poderiam sê-lo sobre qualquer outra pessoa. Igualar-se a seus modelos, celebridades na maior parte dos casos, dá o conforto do pertencimento, a certeza do triunfo. Um anel de diamante extraordinário expande a esfera de significado de seu portador. Adornos de um modo geral intensificam o poder da personalidade de seu portador, operando como uma espécie de radiação emanada, como Georg Simmel, em texto publicado originalmente em 1908, nos explica:

0 adorno aumenta ou amplia a impressão da personalidade, porquanto actua, por assim dizer, como uma emanação sua. Por isso, os metais reluzentes e as pedras preciosas foram, desde sempre, a sua substância; são "adorno" num sentido mais estrito do que a indumentária ou o penteado, os quais todavia também "adornam". Pode falar-se de uma radioactividade do homem no sentido de que, à volta de cada um, se encontra, por assim dizer, uma esfera mais ou menos ampla de significado irradiante, na qual mergulham todos os que com ele tenham de lidar - uma esfera constituída por uma textura inextricável de elementos corpóreos e anímicos. (SIMMEL, 2014, pp. 67-68)

0 padrão de beleza feminina tradicional é criação masculina. Sobre a materialidade do corpo são construídas práticas identitárias e, mais do que isso, são estabelecidos os critérios para reconhecer o corpo abjeto, aquele não adequadamente submetido às regras da generificação, ou o corpo sem dono e sem diamante.

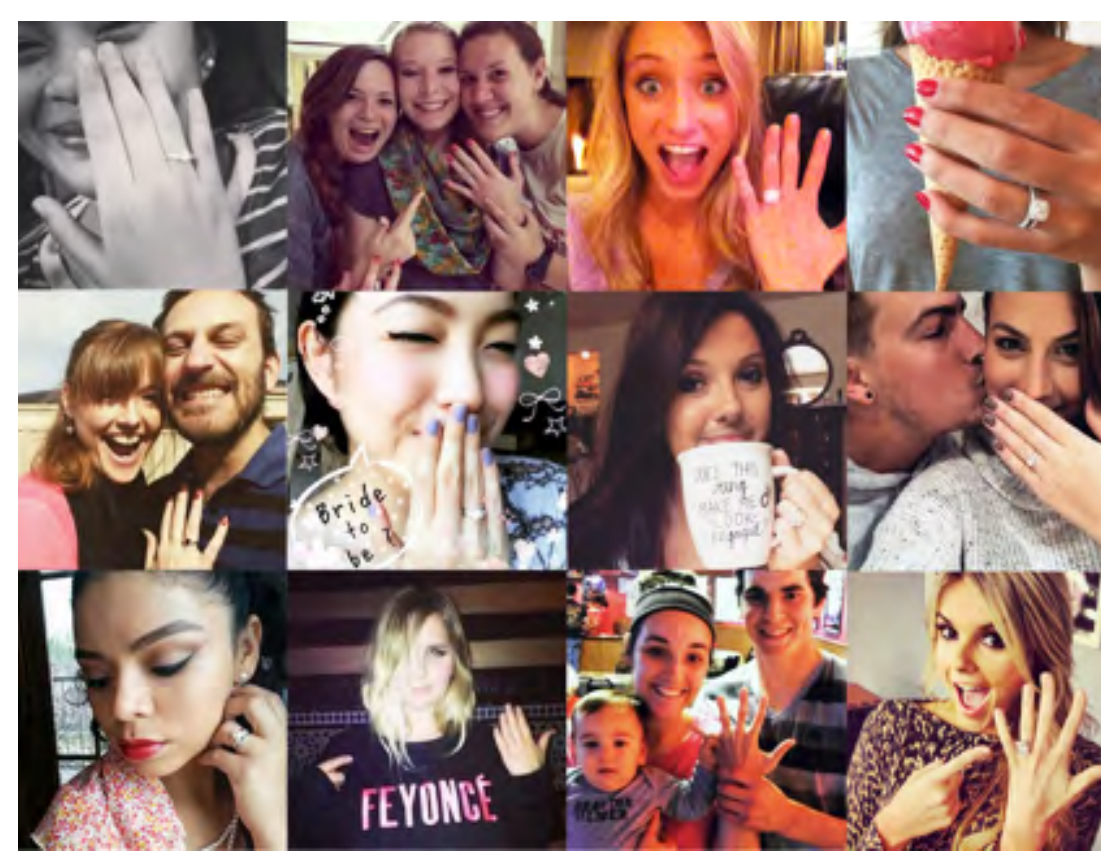

Figura 3 - Mulheres posam com seus anéis de noivado ao redor do mundo. Fonte: Instagram ${ }^{8}$.

Práticas discursivas criam normas para cada gênero. A sociedade diz às mulheres que, exatamente como as celebridades das quais sempre sabemos 
quantos quilates estão portando nos dedos, elas serão avaliadas pelo diamante que ganham. Já os homens são ensinados a comprá-los para presentear sua eleita. As informações cruzadas não param aí, elas seguem infinitamente, como Judith Butler explica:

Em primeira instância, então, a performatividade de gênero gira em torno dessa metalepsia, a maneira pela qual a antecipação de uma essência de gênero produz o que ela postula como fora de si mesma. Em segundo lugar, a performatividade não é um ato singular, mas uma repetição e um ritual, que alcança seus efeitos por meio de sua naturalização no contexto de um corpo, entendido, em parte, como uma duração temporal culturalmente sustentada. (BUTLER, 2007 - tradução nossa) ${ }^{9}$

Curiosamente, os diamantes crescem na medida em que as mulheres alcançam postos mais altos no mercado de trabalho. Parece que há um mecanismo de correção que faz com que o diamante almejado tenha sempre um valor proibitivo para a mulher. Mesmo assim, a De Beers criou a campanha Raise your right hand (Levante a sua mão direita), destinada pela primeira vez especificamente ao público feminino, em 2003. Sempre é possivel ampliar o mercado, dizendo que uma mulher deve ter vários diamantes. 0 anel da mão direita fala sobre os espaços conquistados, a independência feminina, mas não abandona nenhuma das marcações típicas da heteronormatividade compulsória e ainda consegue ser misógina em algumas imagens e em alguns textos da campanha publicitária ao apresentar uma figura feminina erotizada, sempre sublinhando, com iluminação, ora os diamantes nos dedos, ora os genitais. Uma das frases da campanha é: Sua mão esquerda balança o berço. Sua mão direita governa o mundo (ANDERSON, 2016) ${ }^{10}$.

Ao mesmo tempo que o anel de noivado inaugura uma interdição sobre a mulher que passa a uma relação de exclusividade, ele identifica, com sua ausência, o corpo abjeto que precisa ser corrigido e sinaliza as solteiras e disponiveis para o seu grupo social. Como as imagens têm estatuto de lei em nossa sociedade, até mais do que o próprio anel, parece imprescindivel realizar a sua foto, nem que para isso seja necessário fazer cirurgias plásticas e aprender as poses corretas. Talvez seja justo, nesse ponto, que o anel da mão direita ganhe seu sentido. Ele faz uma correção temporária do corpo abjeto, fora da norma, colocando uma marca que informa que ela não está solteira porque quer ou porque não está apta, mas porque ainda não achou seu par. A depreciação da mulher solteira fica suspensa ao percebermos que ela está a um passo de alcançar seu objetivo, já que se mantém como consumidora de símbolos carregados de significados de gênero.

A artista pop Beyoncé avisa em sua música Single Ladies: porque se você gostava, então você deveria ter colocado um anel nele (STEWART, 2008 - tradução nossa) $)^{11}$. Para os homens, ela indica que só o anel no dedo fecha o acordo entre as partes. Para as mulheres, ela ressalta que não se deve perder tempo com quem não estiver disposto a abnegadamente adquirir o anel de diamante. 
A cantora usava no vídeo seu próprio anel de noivado que, somado com a preciosa luva realizada pela mesma joalheira responsável pela joia, totalizava mais de 10 milhões de dólares. Seguindo seu próprio conselho, ela se encontra no topo da lista dos corpos que não são, sob nenhum aspecto, abjetos.

\section{Conclusão}

As joias, e em especial o anel de noivado de diamante, são adornos que afetam a capacidade da mulher de se apresentar na sociedade, definindo

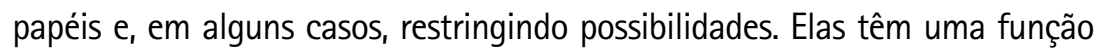
importante na diferenciação tradicionalmente aceita de papéis masculinos e femininos e são auxiliares no reforço permanente das ideias de patriarcado. Historicamente, há exemplos mais contundentes do que o anel, como, por exemplo, os aros que deformam os pescoços femininos na tribo Karen, em Chiang Mai, na Tailândia, ou as pesadas tornozeleiras que impossibilitam caminhadas entre as mulheres da tribo Igbo, na Nigéria (RUSSEL, 2010). Há exemplos que servem simplesmente para diferenciar homens de mulheres, como é o caso dos brincos em meninas recém-nascidas nos paises ibero-americanos. As mulheres indianas são símbolos claros do poder masculino sobre elas e passam a se ornamentar de forma ostensiva, combinando joias da sua família com as da família do marido durante todo o seu casamento. Nas crianças e adolescentes, os ornamentos são muito discretos e na viuvez são completamente interditados, em uma permanência do ritual de jogar-se na pira funerária junto com o marido morto. Além disso, a ornamentação deixa claro que não é necessária atratividade fora da esfera do sexo marital.

Como seria uma joia feminista? Será que é possivel uma joia feminista? Alguns autores joalheiros contemporâneos, embora não tenham a intenção de responder a essa pergunta, brincam com o simbólico inerente ao anel de noivado de diamante e apresentam algumas propostas interessantes que tratam de valor, peso, perenidade.

Colocar anéis de noivado nos homens, comprar anéis comemorativos de divórcio ou o próprio anel da mão direita, nenhuma dessas alternativas parece representar o que seria uma solução para a questão da hegemonia de um padrão que limita as possibilidades das mulheres. Ainda mergulhados no regime contemporâneo de consumo e nas regras da heteronormatividade, é muito dificil imaginar um mundo em que as mulheres sejam inteiramente donas de seus corpos e de seus bens sem se tornarem monstros.

Recebido em: 29-05-2017

Aprovado em: 20-08-2017 


\section{NOTAS}

1 Imagens disponiveis em: <https://collections.vam.ac.uk/item/0121117/fede-ring-unknown/>, <https://collections.vam.ac.uk/item/0118611/ring-unknown/>, <https://collections.vam.ac.uk/item/ 0118499/ring-robinson-andrew/>, <https://collections.vam.ac.uk/item/0118638/ring-unknown/>, <https://collections.vam.ac.uk/item/072506/ring-ring-unknown/>. Acesso em: 25 ago. 2017.

${ }^{2}$ Imagem disponivel em: <http://i.dailymail.co.uk/i/pix/2010/11/19/article-1331191-0C1A3E08000005DC112_306x457.jpg>. Acesso em: 25 ago. 2017.

${ }^{3}$ Imagem disponivel em:<http://theroyalpost.com/wp-content/uploads/2011/11/maxima-a.jpg?w=300>. Acesso em: 25 ago. 2017.

${ }^{4}$ Imagem disponivel em: <http://www.tiffany.com/Engagement/rings/the-tiffany-setting>. Acesso em: 25 ago. 2017.

${ }^{5}$ I prefer a man who lives and gives expensive jewels. A kiss on the hand may be quite continental but diamonds are a girl's best friend. A kiss may be grand but it won't pay the rental on your humble flat, or help you at the automat. (STYNE; ROBIN, 1953)

${ }^{6}$ Imagem disponivel em: <http://www.en.cartier.com/collections/engagement/features/legend/grace-kelly-andprince-rainier-iii.html>. Acesso em: 25 ago. 2017.

${ }^{7}$ Jewellery is often conceived as a sign, as an object that gives meaning. People are used to reading jewellery. (sic) Having said that, I should add that it is also the wearer that makes the meaning of a piece, attributing stories, memories, and their personality to it, charging a piece of jewellery with meaning. (sic) The meaning of jewellery, even author jewellery, is - more than we normally think or would like to admit - dependent on underlying traditions, attributions and systems of value that have a long history; this forms jewellery's own language. (BESTEN, 2011, pp. 24-31.)

${ }^{8}$ Imagens disponiveis em: <https://www.instagram.com/explore/tags/engagementring/>. Acesso em: 1 jun. 2015.

${ }^{9}$ In the first instance, then, the performativity of gender revolves around this metalepsis, the way in which the anticipation of a gendered essence produces that which it posits as outside itself. Secondly, performativity is not a singular act, but a repetition and a ritual, which achieves its effects through its naturalization in the context of a body, understood, in part, as a culturally sustained temporal duration. (BUTLER, 2007)

${ }^{10}$ Your left hand rocks the cradle. Your right hand rules the world. (ANDERSON, 2016)

${ }^{11}$ Cause if you liked it, then you should have put a ring on it. (Stewart, 2008)

\section{REFERÊNCIAS}

ANDERSON, A. Put a right-hand ring on it. In: The Jewellery Editor. Londres, 12 out. 2016. Article. Disponivel em: <http://www.thejewelleryeditor.com/jewellery/article/right-hand-rings-meaningsignificance-trend/>. Acesso em: 12 out. 2016.

BAIN \& CO. The global diamond industry: portrait of growth. [Arquivo eletrônico] Boston: Bain \& Co., 2012. Disponivel em: <http://www.bain.com/publications/articles/global-diamond-industry-portrait-ofgrowth.aspx>. Acesso em: 14 jun. 2015.

BESTEN, Liesbeth den. On jewellery: a compendium of international contemporary art jewellery. Stuttgart: Arnoldsche, 2011.

BRIDES TO BE. The 8 most subtle ways to flash your engagement ring, as demonstrated by our favourite celebrities. Disponível em: $<$ http://www.bridetobe.com.au/article/planning-latest-trends-i-lovemy-ring-celebrities-showing-off-their-rings>. Acesso em: 14 jun. 2015.

BUTLER, Judith. Gender trouble: feminism and the subversion of identity. [Kindle eBook] New York: Routledge, 2007. Epub ISBN 9780415389556 version 1.0.

ELLIN, Abby. Raise your hand for an engagement selfie. In: The New York Times. New York City, 23 mai. 2014. Weddings. Disponivel em: <http://www.nytimes.com/2014/05/25/fashion/weddings/raise-yourhand-for-an-engagement-selfie.html?_r=0>. Acesso em: 14 jun. 2015. 
FLUSSER, Vilém. Filosofia da caixa preta: ensaios sobre uma futura filosofia da fotografia. Rio de Janeiro: Relume Dumará, 2002.

GIDDENS, Anthony. Tradition. In:___ Runaway world: how globalisation is reshaping our lives. [Kindle eBook]. Londres: Profile Books, 2011. Epub ASIN: B00505SWOQ version 2.0.

HABERMAS, Tilmann. Diamonds are a girl's best friend: the psychology of jewellery as beloved objects. In: Lindermann, Wilhelm (Ed.). Thinking jewellery: on the way towards a theory of jewellery. Stuttgard: Arnoldsche, 2011, pp. 95-107.

MCNEIL JR, Donald. A diamond cartel may be forever; The hereditary leader of De Beers pursues postapartheid growth. In: The New York Times. New York City, 12 jan. 1999. Business Day. Disponivel em: $<$ <ttp://www.nytimes.com/2005/02/28/style/in-a-show-of-power-women-raise-a-glittery-right-hand. html >. Acesso em: 14 jun. 2015.

MICHAULT, Jessica. In a show of power, women raise a glittery right hand. In:The New York Times. New York City, 28 fev. 2005. Fashion and Style. Disponivel em: <http://www.nytimes.com/2005/02/28/style/ina-show-of-power-women-raise-a-glittery-right-hand.html>. Acesso em: 14 jun. 2015.

OLTUSKI, Alicia. Precious objects: a story of diamonds, family and a way of life. Nova York: Scribner, 2011.

PERRET, Vivianne. Pour le meilleur et our le pire. In : pierreries qui ont fait l'Histoire. Paris: Vuibert, 2012, pp. 279-284.

POST, Jeffrey E. The National Gem Collection of the Smithsonian Institution. Nova York: Harry M. Abrams, 1997.

RUSSEL, Rebecca Ross. Gender and jewelry: a feminist analysis. [Kindle Book]. CreateSpace, 2010. Epub ISBN 9781452882536 version 1.0.

SCARISBRICK, Diana. Love, marriage and friendship rings. Rings: jewelry of power, love and loyalty. London: Thames \&t Hudson, 2013, pp. 59-119.

SIMMEL, Georg. Psicologia do adorno. In: . Filosofia da moda. Lisboa: Texto \&t Grafia, 2014, pp. 65-78.

SLEDZIEWSKI, Elisabeth G. Jewellery as an indicator of gender. In: Lindermann, Wilhelm (Ed.). Thinking jewellery: on the way towards a theory of jewellery. Stuttgard: Arnoldsche, 2011.

STEWART, C; HARRELL, T; KNOWLES, B. NASH, T.Y. Single Ladies. Álbum I am... Sacha Fierce. São Paulo: Sony, 2008, Áudio CD.

SULLIVAN, Courtney. How Diamonds Became Forever. In: The New York Times. New York City, 3 mai. 2013. Weddings. Disponivel em: <http://www.nytimes.com/2013/05/05/fashion/weddings/howamericans-learned-to-love-diamonds.html>. Acesso em: 14 jun. 2015.

TIBURI, Marcia. 0 plástico essencial. In: Revista Cult. São Paulo: Bregantini, ano 18, n. 198, p. 11, fev. 2015.

TIFFANY \& CO. This is a Tiffany ring. New York City: Tiffany \& Co., 2015. 